\title{
Thyristor Based DC Motor Control with Improved PF \& THD
}

\author{
Rohit Gupta ${ }^{1}$ and Ruchika ${ }^{2}$ \\ ${ }^{1}$ Department of Electrical and Electronics Engineering, Noida Institute of Engineering \& \\ Technology, Gr. Noida, India \\ ${ }^{2}$ Department of Electrical and Instrumentation Engineering, Thapar University, Patiala, India \\ rohit.udai@yahoo.in, ruchika.mehta@thapar.edu
}

\begin{abstract}
DC motors are widely used in industries because of its versatile characteristics and because of power electronics devices its controlling is becoming sophisticated and precise, but on the other hand because of the power electronics devices power factor and total harmonics distortion problem is becoming more prominent. In this paper DC motor control methodology is proposed which includes thyristor based converters but with improved power factor and total harmonics distortion.
\end{abstract}

Keywords: AC/DC converter, DC motor, Power Factor, Speed control, Total Harmonic Distortion.

\section{Introduction}

Because of low cost, less complex control structure and wide range of speed and torque, DC motor are popular in industry. Available methods of speed control of DC drives are field control, armature control and armature resistance control methods [1]. Speed of a DC motor can be controlled easily in both the ranges above and below the base speed. Most of the time, DC motors are customized at the time of installation as per the need which makes them irreplaceable. Armature voltage control method of speed control of DC drive is popularly used in which controlled rectifier or chopper are involved, though due to power electronics elements, an undesirable nonlinear torque speed characteristics are observed [2].

In past, many researchers worked on various converter topologies of DC motor control for different industrial applications [5, 6, 7, 8, 9], but all of them are thyristor based. For simulation of various topologies MATLAB with its tool boxes like Simulink and SimPowerSystem are used [3, 7].

\section{Mathematical modelling of DC motor}

To analyse the torque speed characteristics, power factor and total harmonics distortion, the dynamic and steady-state model of separately excited DC motor is required. Figure 1 shows the schematic representation of the model of a separately excited DC motor, in which $e_{a}$ is the terminal voltage applied to the motor, $R_{a}$ and $L_{a}$ are the resistance, and inductance of the armature circuit respectively, $R_{f}$ and $L_{f}$ are the resistance, and inductance of the field circuit respectively, $e_{b}$ is generated back emf and $T_{m}$ is the electromagnetic torque developed by the motor. The related DC Motor parameters are mentioned in appendix A.

Due to the interaction of field flux with current in armature conductors, the torque is produced which is given by Eq. (1)

$$
T_{m}=K_{t} \phi i_{a}
$$

Here $K_{t}$ is a constant depending on motor windings and geometry and $\phi$ is the flux per pole due to the field winding. The direction of armature current decides the direction of the

Received: June $11^{\text {st }}, 2013$. Accepted: December $13^{\text {rd }}, 2013$ 
torque produced. When armature rotates, the flux linking the armature winding will vary with time and therefore according to Faraday's law, an emf will be induced across the winding. This generated emf, known as the back emf, depends on speed of rotation as well as on the flux produced by the field and given by Eq. (2)

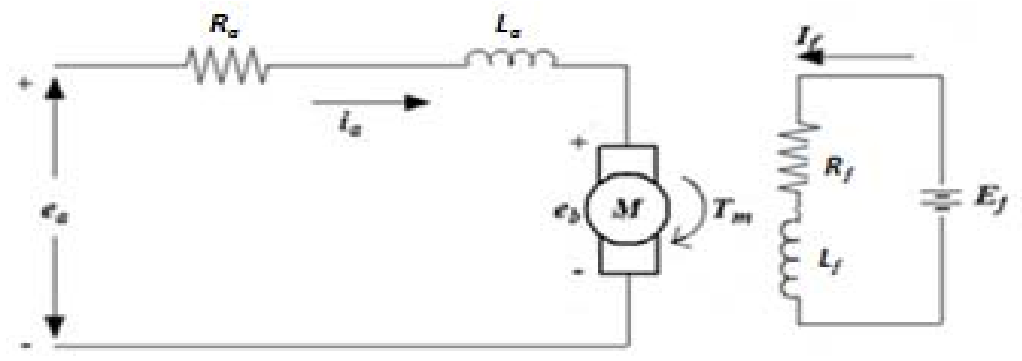

Figure 1. Equivalent circuit of separately excited DC motor

$$
e_{b}=K_{t} \phi \omega
$$

By applying KVL at input side of in figure 1,

$$
e_{a}=i_{a} R_{a}+L_{a} \frac{d i_{a}}{d t}+e_{b}
$$

In steady state condition,

$$
E_{a}=I_{a} R_{a}+E_{b}
$$

In terms of torque and speed, the steady state equation will be given by Eq. (5)

$$
E_{a}=\frac{T_{m}}{K_{t} \phi} R_{a}+K_{t} \omega \phi
$$

So,

$$
\omega=\frac{E_{a}}{K_{t} \phi}-\frac{T_{m}}{\left(K_{t} \phi\right)^{2}} R_{a}
$$

Thus from the above equation it is clear that speed can be controlled by varying three parameters, namely $E_{a}, R_{a}$, and $\phi$. The three methods of speed control are following:

- Armature voltage controlled $\left(E_{a}\right)$.

- Armature resistance controlled $\left(R_{a}\right)$.

- Flux controlled $(\phi)$.

Adding external resistor to the DC drive to control the speed of DC motor is not a healthy practice as large part of energy get loosed in terms of heat due to the external resistor $R_{\text {ext }}$. Armature voltage controlled is preferred for speed up to rated speed (base speed), and flux control for speed beyond rated speed but at the same time the maximum torque capability of the motor is reduced since for a given maximum armature current, the flux is less than the rated value and so as the maximum torque produced is less than the maximum rated torque [4]. 
Figure 2 illustrate the ideal torque speed characteristic which reflects equation (6), using armature voltage control method in which the voltage applied across the armature $e_{a}$ is varied keeping field voltage constant [10].

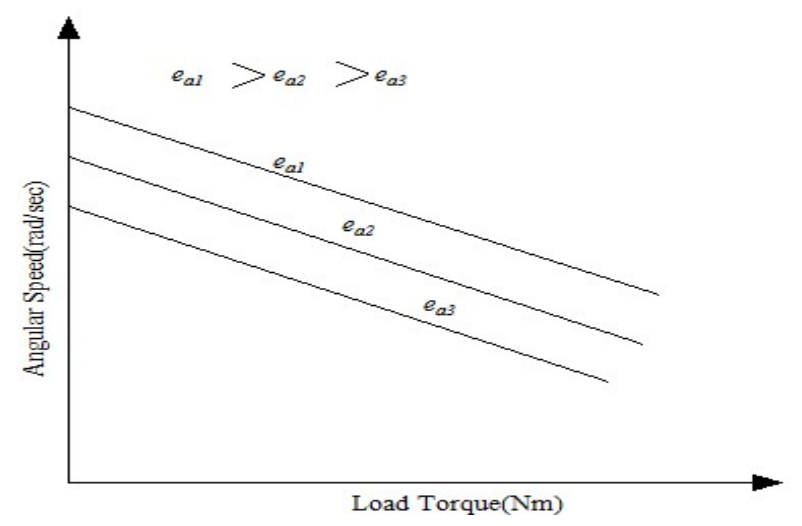

Figure 2. Torque speed characteristics of the separately excited DC motor at different armature voltages

\section{Thyristor based techniques of DC motor speed control}

Figure 3 shows a separately excited DC motor fed through single phase half wave converter. It offers only one quadrant drive. Such type of drives, are used up to about $0.5 \mathrm{~kW}$ DC motor.

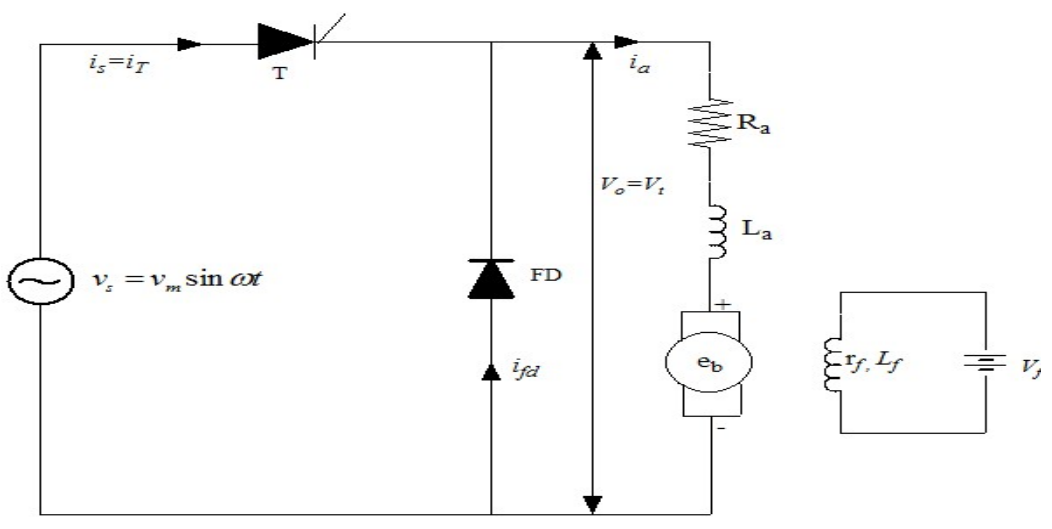

Figure 3. Single phase half wave converter drive

For single phase half wave converter, average output voltage of converter can be calculated as, given by Eq. (7)

$$
V_{0}=\frac{V_{m}}{2 \pi}(1+\cos \alpha), \text { for } 0<\alpha<\pi
$$

An ideal DC source is preferred over half wave converter for field circuit of half wave converter drive otherwise the magnetic losses of the motor increase due to high ripple content in the field excitation current. A separately excited DC motor fed through single phase semiconverter is shown in figure 4. This converter also offer only one quadrant drive and is used up to $15 \mathrm{~kW}$ DC drives. 


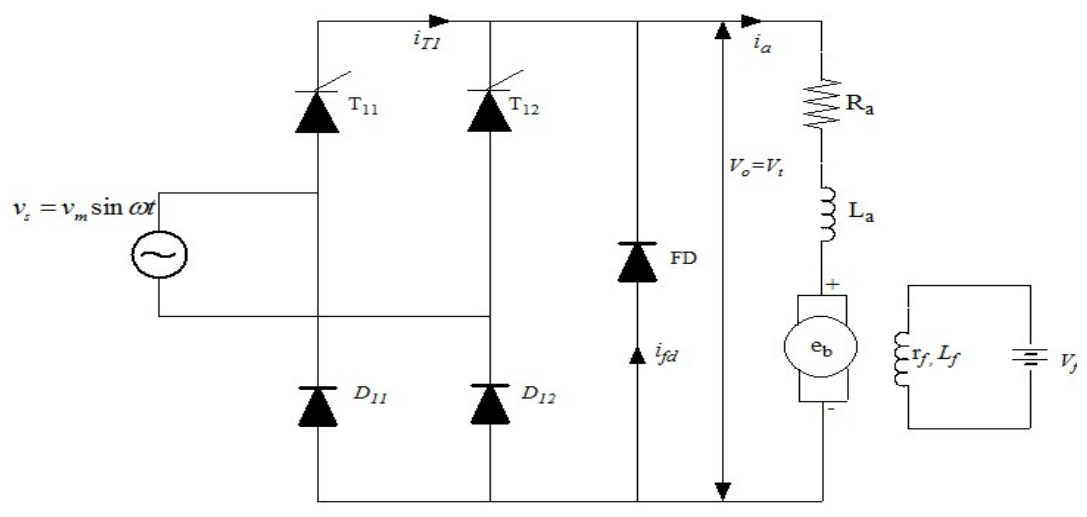

Figure 4. Single phase semi converter drive

With a single phase semiconverter in the armature circuit, equation (8) gives the average armature voltage as,

$$
V_{0}=V_{t}=\frac{V_{m}}{\pi}(1+\cos \alpha), \text { for } 0<\alpha<\pi
$$

A single phase full converter drive offers a two quadrant drive operation and is limited to applications up to $15 \mathrm{~kW}$, which is shown in figure 5 . The armature converter gives $+V_{o}$ or $-V_{o}$ and allows operation in the first and fourth quadrant. The converter in the field circuit could be semi, full or even dual converter. The reversal of the armature or field voltage allows operation in the second and third quadrant.

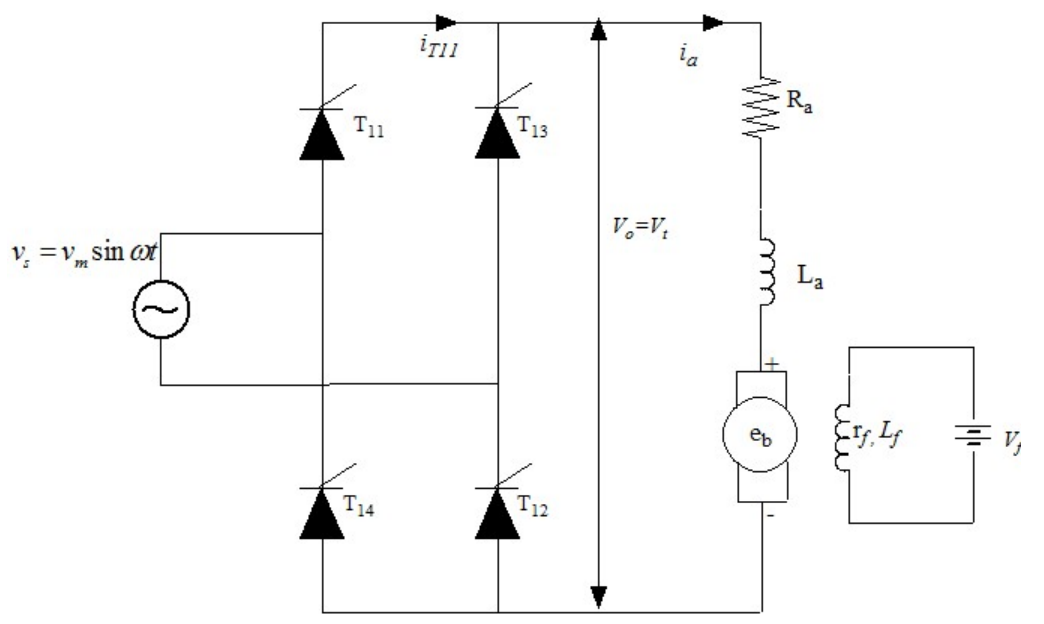

Figure 5. Single phase full converter drive

The average armature voltage in armature circuit for single phase full converter drive is given by Eq. (9)

$$
V_{0}=V_{t}=\frac{2 V_{m}}{\pi}(1+\cos \alpha), \text { for } 0<\alpha<\pi
$$


To realize single phase dual converter, two single phase full converters are connected as shown in figure 6.

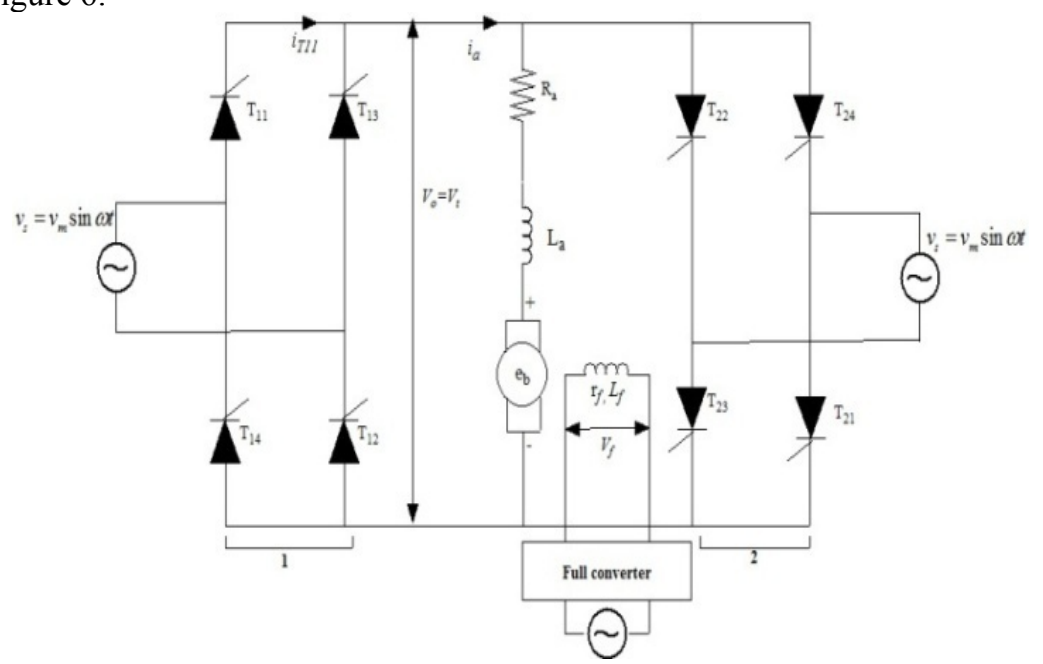

Figure 6. Single phase dual converter drive

In figure 6, there are two single phase full wave converters either converter 1 operates to supply a positive armature voltage $V_{o}$, or converter 2 operates to supply negative armature voltage $-V_{o}$. Converter 1 provides operation in first and fourth quardants, and converter 2 provides operation in second and third quardants.It is four quardant drive and provides four modes of operation: forward powering, forward braking (regenration), reverse powering, and reverse breaking (regeneration). The field converter could be a full wave converter, a semiconverter, or a dual converter.

If converter 1 operates at a firing angle of $\alpha_{l}$ then equation (10) gives the armature voltage as,

$$
V_{0}=V_{t}=\frac{V_{m}}{\pi}\left(1+\cos \alpha_{1}\right), \text { for } 0<\alpha<\pi
$$

And similarly, if converter 2 operates at a firing angle of $\alpha_{2}$ then equation (11) gives the armature voltage as, [11].

$$
V_{0}=V_{t}=\frac{V_{m}}{\pi}\left(1+\cos \alpha_{2}\right)
$$

\section{Methodology}

Harmonics puts very adverse effects on the power system, the biggest problem with harmonics is voltage waveform distortion. The relation can be deduced between the fundamental and distorted waveforms by mathematical tool Fast Fourier Transform (FFT), in which the square root of the sum of squares of all harmonics generated by load is found out and then that number is divided by the nominal frequency. Using FFT, total harmonic distortion (THD) contained by the nonlinear current or voltage waveform is determined. Harmonics can cause overloading and overheating of load which can result in load failure.

Rectifier is the main component of any power system based system. The input stage of any AC-DC converter comprise of a full-bridge rectifier followed by a large filter capacitor. The input current of such a rectifier circuit comprises of large discontinuous peak current pulses that result in high input current harmonic distortion. The high distortion of the input current occurs due to the fact that the diode rectifiers conduct only for a short period. This period 
corresponds to the time when the mains instantaneous voltage is greater than the capacitor voltage. Since the instantaneous mains voltage is greater than the capacitor voltage only for very short period of time, when the capacitor is fully charged, large current pulses are drawn from the line during this short period of time and that will lead to poor power factor.

So from above discussion it can be concluded that if the shape of input current or voltage can be maintained as a sinusoidal wave, the power factor and total harmonic distortion (THD) both can be improved.

Many input current wave shaping methods have been proposed to overcome disadvantages of conventional rectifiers like high input current harmonic components, low power factor, low rectifier efficiency etc. Those wave shaping method can be broadly classified as active, passive and hybrid methods. In the past, designers have used three passive wave shaping methods to improve the input power factor and reduce total harmonic distortion THD of conventional acto-dc rectifiers which are Input passive filter method, resonant passive input filters method and Ferro resonant transformer method. [12]

Among the passive wave shaping methods proposed earlier, the novel method proposed in 1990 is superior to others in reducing the input current harmonics and improving the input power factor [13]. The novel method can efficiently improve the power factor, however, the further improvement of the input power factor is difficult to be achieved, and the input current's total harmonic distortion is still high, which is the main disadvantage of the novel topology. This novel method uses an input parallel resonant tank of capacitor and inductor to remove the third harmonic component from the input current. The input power factor increases because the third harmonic component is the main reason of the low input power factor. The advantages of the this method over the conventional method include: (i) low input current THD (ii) higher input power factor, and (iii) increase in the efficiency of the rectifier. Fig. 7 shows the block diagram how the wave shaping method is used to improve the power factor and total harmonic distortion of DC drives.

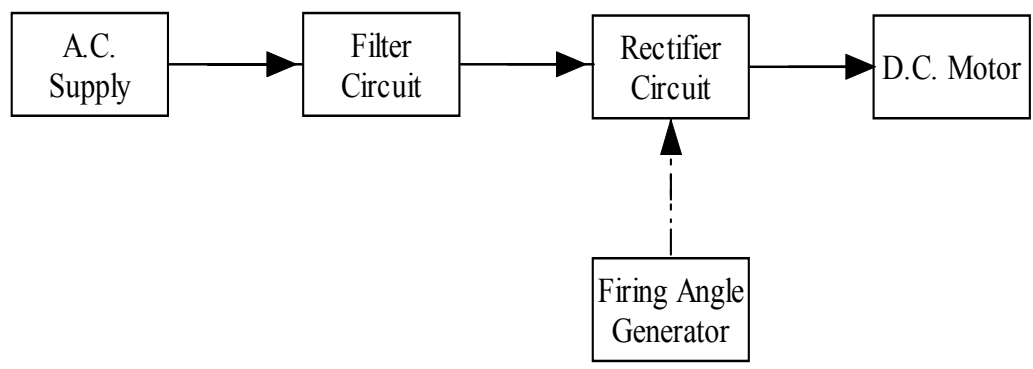

Figure 7. Block diagram of methodology used

\section{Simulation Results}

Some assumptions were made to analyze the circuits which are the following:-

- Ideal filter components.

- The forward voltage drop and reverse leakage current of diodes are neglected.

Five different passive power factor improvement topologies for low power output with $220 \mathrm{volt} / 50 \mathrm{~Hz}$ ac input have been considered.

The five different topologies are:-

1. Conventional single phase diode rectifier with filter capacitor.

2. Single phase diode rectifier with $\mathrm{LC}$ filter.

3. Single phase diode rectifier circuit with parallel input resonant filter.

4. Single phase diode rectifier circuit with series input resonant filter. 
5. Single phase diode rectifier circuit with improved parallel input resonant filter. Table 1 shows the specifications of the components used in the topologies.

Table 1. Specification of the components

\begin{tabular}{|c|c|}
\hline Components & Specifications \\
\hline AC supply & $220 \mathrm{~V} / 50 \mathrm{~Hz}$ \\
\hline Diodes & DIN 4936 \\
\hline Resistances & $100 \Omega$ \\
\hline Capacitors & $60 \mathrm{mF} / 0.1 \mathrm{mF} / 100 \mathrm{mF} / 500 \mu \mathrm{F}$ \\
\hline Inductor & $1 \mathrm{mH} / 50 \mathrm{mH} / 5 \mathrm{mH} / .005 \mathrm{mH}$ \\
\hline
\end{tabular}

Figure 8 shows the simulation prototype of different passive power factor improvement topologies with their respective input current and voltage waveform.
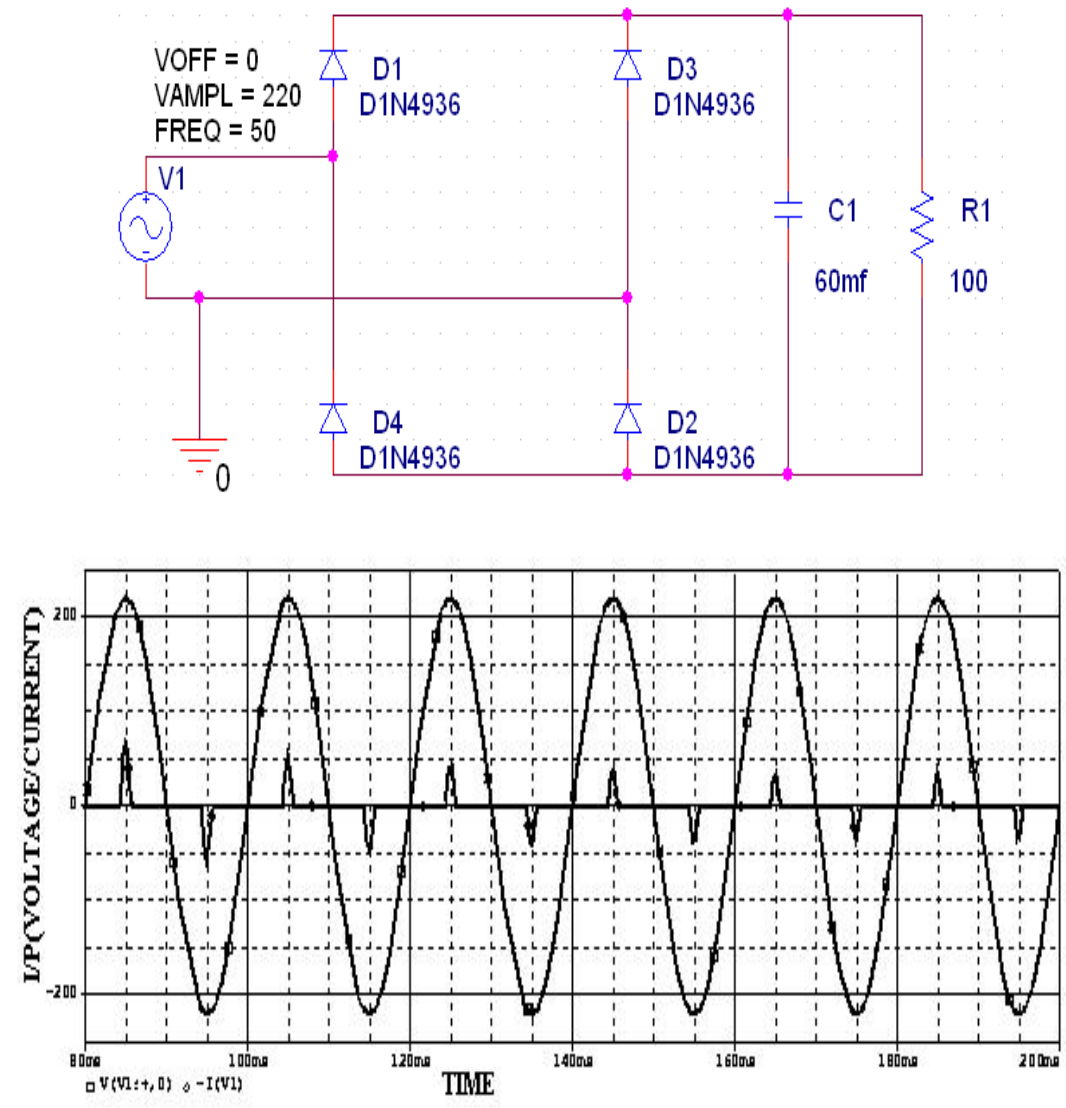

(a). 
Rohit Gupta, et al.
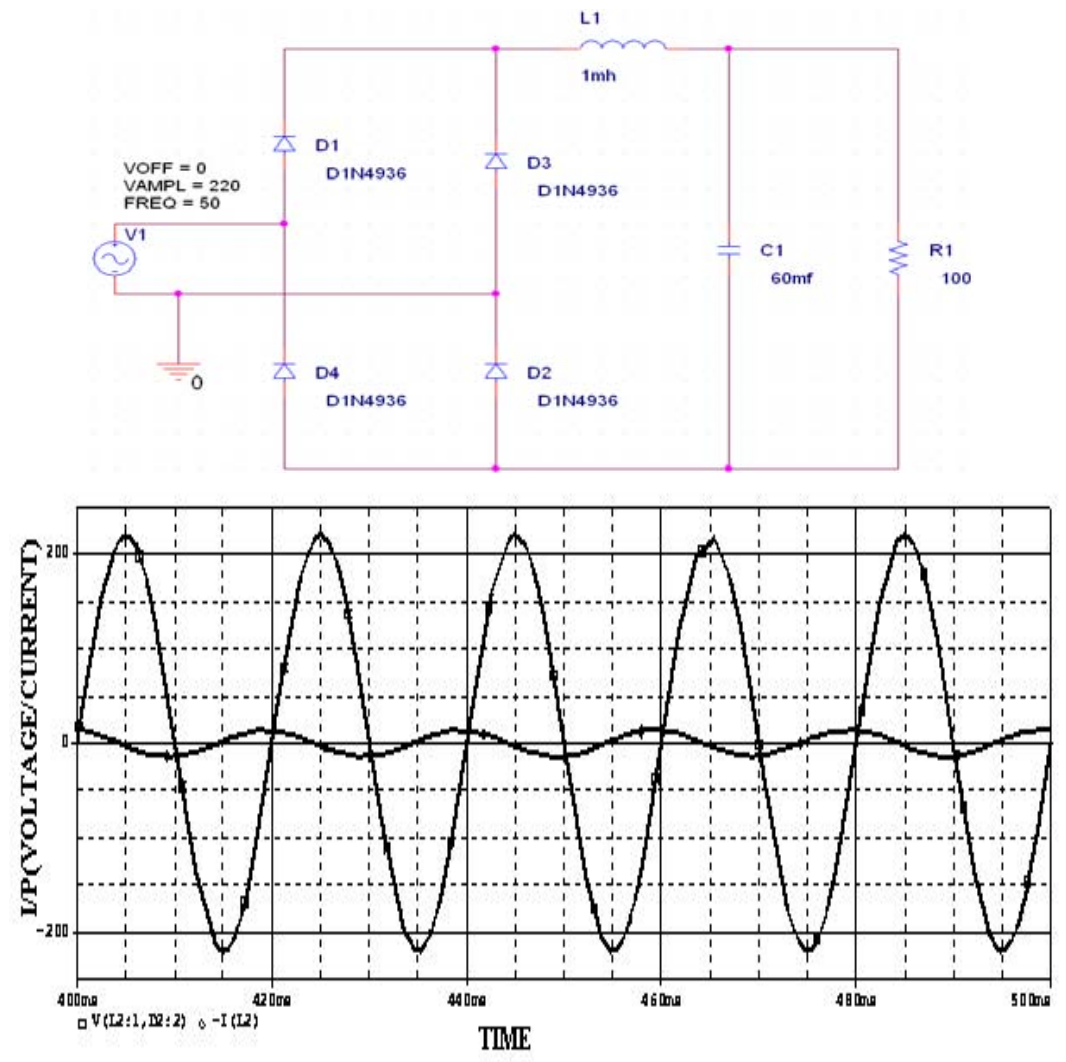

(b).
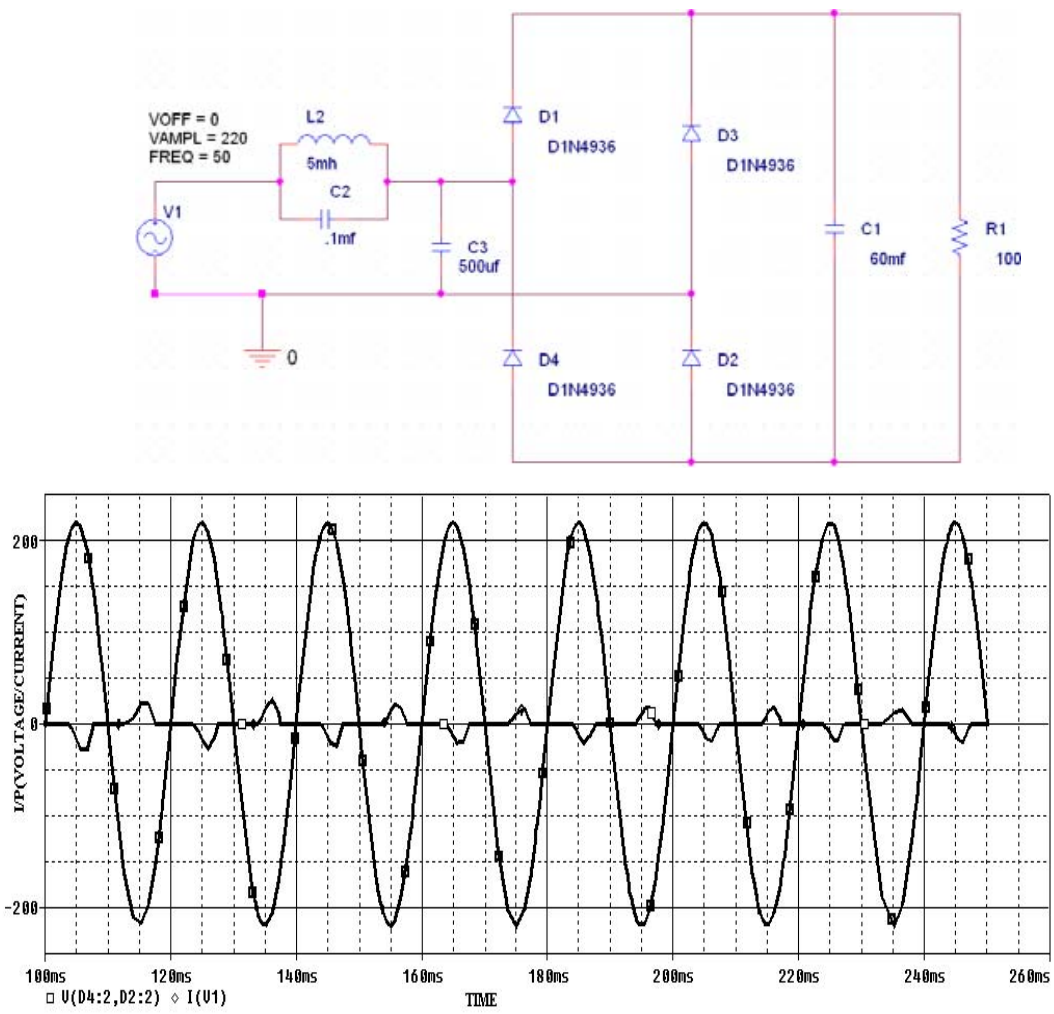

(c). 

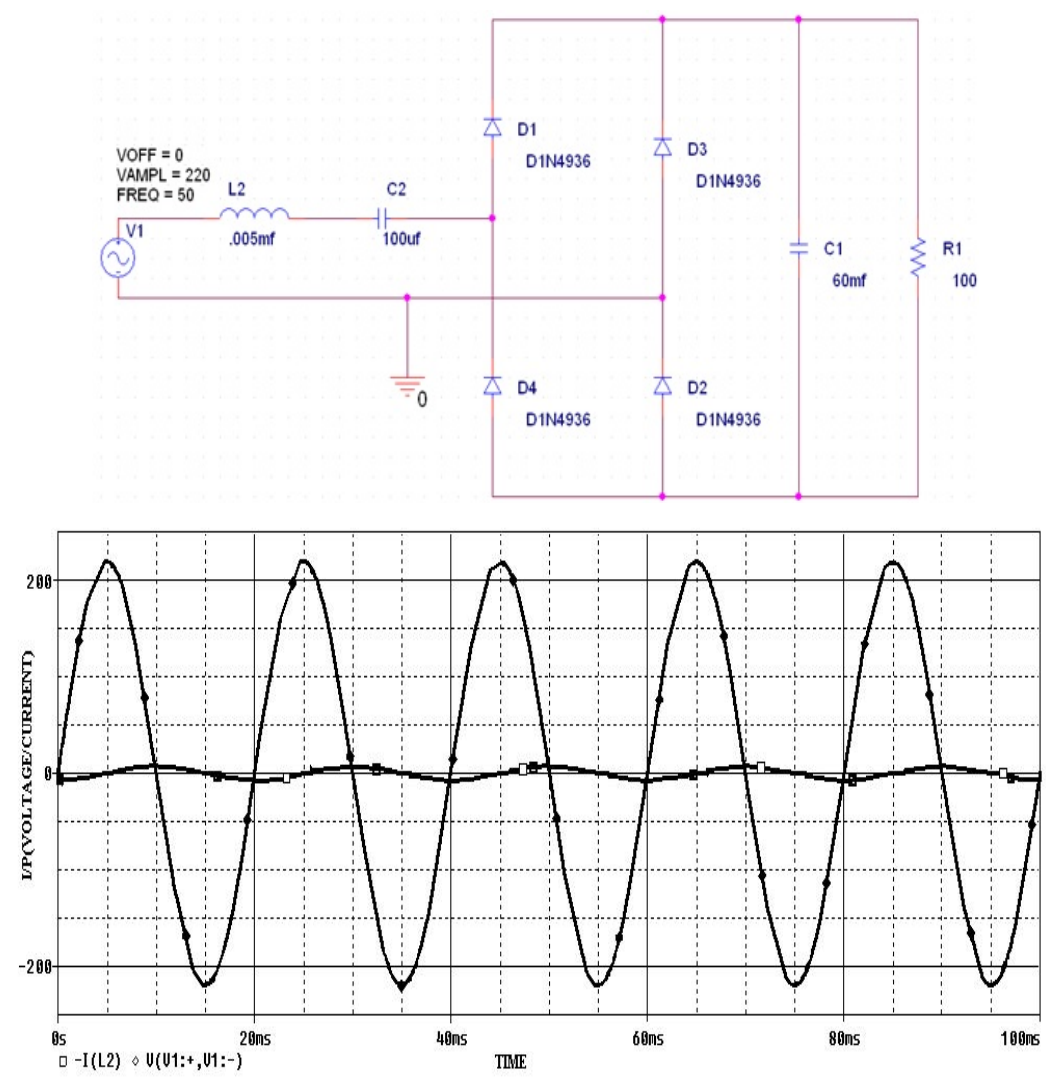

(d).

Figure 8(a) shows the simulated prototype of a conventional single phase diode rectifier with filter capacitor, in which the harmonics of input current, which are highly undesirable, are seen. The output filter capacitor value $\left(\mathrm{C}_{1}\right)$ is calculated using eq. 13 .

$$
C_{1}=\frac{1}{4 f R}\left[1+\frac{1}{\sqrt{2 R F}}\right]
$$

\footnotetext{
$R F$ :- ripple factor

$R R$ :- output resistance

$f f$ :- frequency of ac source
}

To get minimum ripple factor we have chosen $\mathrm{C}_{1}=60 \mathrm{mF}$ (milli farads).

Figure 8(b) shows the simulated prototype of a conventional single phase diode rectifier with LC filter. The inclusion of the inductor results in larger conduction angle of the current pulse and reduced peak and r.m.s values, and the waveform of input current and input voltage show that the harmonics of input current are reduced.

For low values of inductance the input current is discontinuous and pulsating. However, it is shown [14] that even for infinite value of the inductance, the PF cannot exceed 0.9 for this kind of arrangement. 

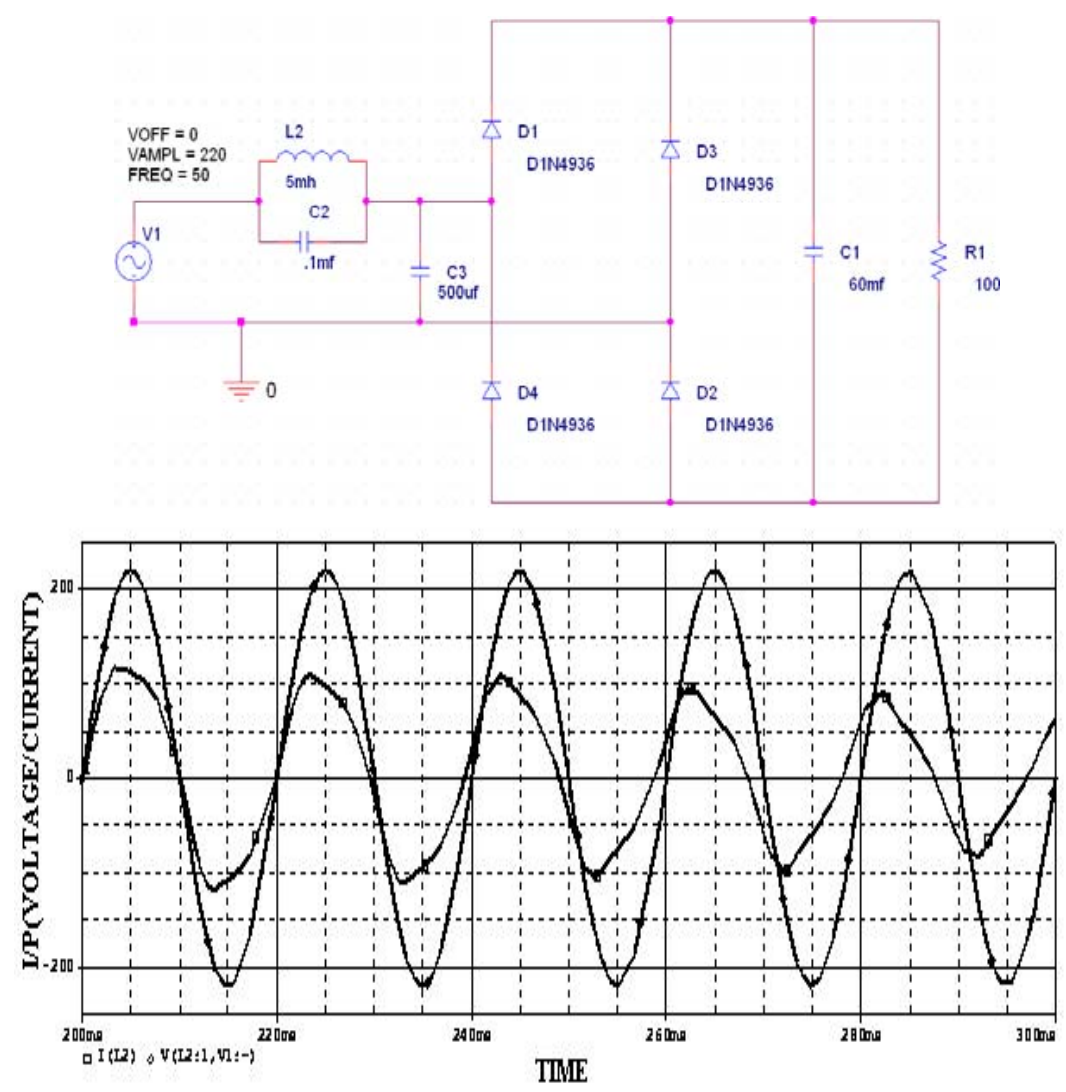

(e).

Figure 8. Simulation prototype of various filter circuit with their I/P voltage and current waveform

(a). Single phase diode rectifier with filter capacitor

(b). Single phase diode rectifier with LC filter

(c). Single phase diode rectifier with parallel input resonant filter

(d). Single phase diode rectifier with series input resonant filter

(e). Single phase diode rectifier with improved parallel input resonant filter

Figure $8(\mathrm{c})$ shows the simulated prototype of single phase diode rectifier using parallel resonant circuit and input current and voltage waveform, which shows the prominent improvement in the harmonics and the value of inductor and capacitor for this topology are calculated using the analysis discussed below.

The $\mathrm{n}^{\text {th }}$ harmonic component of the equivalent impedance of the input parallel resonant filter is given by eq. 14 .

$$
Z_{n}=\frac{n X_{L_{2}} * \frac{X_{c_{2}}}{n}}{j n X_{L_{2}}-j \frac{X_{c_{2}}}{n}}
$$

$X_{L_{2}}$ is impedance of input resonant inductor $\mathrm{L}$ at fundamental frequency.

$X_{C_{2}}$ is impedance of input resonant capacitor $\mathrm{C}$ at fundamental frequency.

The third harmonic impedance of the input resonant filter will be infinity (theoretically). 
Therefore,

$$
\begin{aligned}
& 3 X_{L_{2}}=\frac{X_{C_{2}}}{3} \\
& \text { and } \\
& L_{2}=\frac{1}{9 \omega^{2} C_{2}} \\
& \text { Where } \omega=2 \pi f \text { and is } f \text { in } \mathrm{Hz} .
\end{aligned}
$$

Figure 8(d) the simulated prototype of a single phase diode rectifier with series input resonant filter with its input voltage and current waveform is shown in fig. 8(d). The values of inductor and capacitor considered in the prototype are calculated using the analysis discussed below.

For a series resonant filter at the input end of a single phase rectifier, the capacitance $\mathrm{C}_{2}$ and $\mathrm{L}_{2}$ is chosen such that the resonance condition is satisfied, and the minimum ripple is achieved.

$$
\omega=\frac{1}{\sqrt{L_{2} C_{2}}}
$$

Where

$$
\omega=2 \pi f \text { and } f \text { is in } \mathrm{Hz}
$$

Figure 8(e) shows the simulated prototype of a proposed single phase diode rectifier circuit with improved parallel input resonant filter with its input current and voltage waveform, for which values of $\mathrm{C}_{3}$ are chosen ranging from $100 \mu \mathrm{f}$ (micro farads) to $1 \mathrm{mf}$ (milli farads) and is selected such that the input power factor at rated output power reaches its peak value.

Table 2 shows the calculated parameters for single phase diode rectifier circuit with various filter topologies in tabulated form, which shows improved parallel input resonant filter topology performs well amongst other topologies for which power factor is 0.931 and total harmonic distortion reduced to 5.591 .

Table 2. Parameters for various filter topologies

\begin{tabular}{|l|c|c|c|c|c|}
\hline Type of Filter /Parameters & PF & DF & CDF & HF & \% THD \\
\hline $\begin{array}{l}\text { Single phase diode rectifier } \\
\text { with filter capacitor }\end{array}$ & 0.215 & 0.999 & 0.215 & 4.527 & 176.9 \\
\hline $\begin{array}{l}\text { Single phase diode rectifier } \\
\text { with LC filter }\end{array}$ & 0.3629 & 0.967 & 0.375 & 2.471 & 84.09 \\
\hline $\begin{array}{l}\text { Single phase diode rectifier } \\
\text { with parallel input resonant } \\
\text { filter }\end{array}$ & 0.592 & 0.919 & 0.644 & 1.186 & 23.39 \\
\hline $\begin{array}{l}\text { Single phase diode rectifier } \\
\text { with series input resonant } \\
\text { filter }\end{array}$ & 0.64 & 0.953 & 0.679 & 1.08 & 10.12 \\
\hline $\begin{array}{l}\text { Single phase diode rectifier } \\
\text { with improved parallel input } \\
\text { resonant filter }\end{array}$ & 0.931 & 0.99 & 0.94 & 0.36 & 5.591 \\
\hline
\end{tabular}

It can be concluded from table 2 that improved parallel resonant filter topology gives the best result in terms of power factor and total harmonic distortion, so a simulation model of the same topology with different converter drives are described in section III, which are shown in figure 9. 


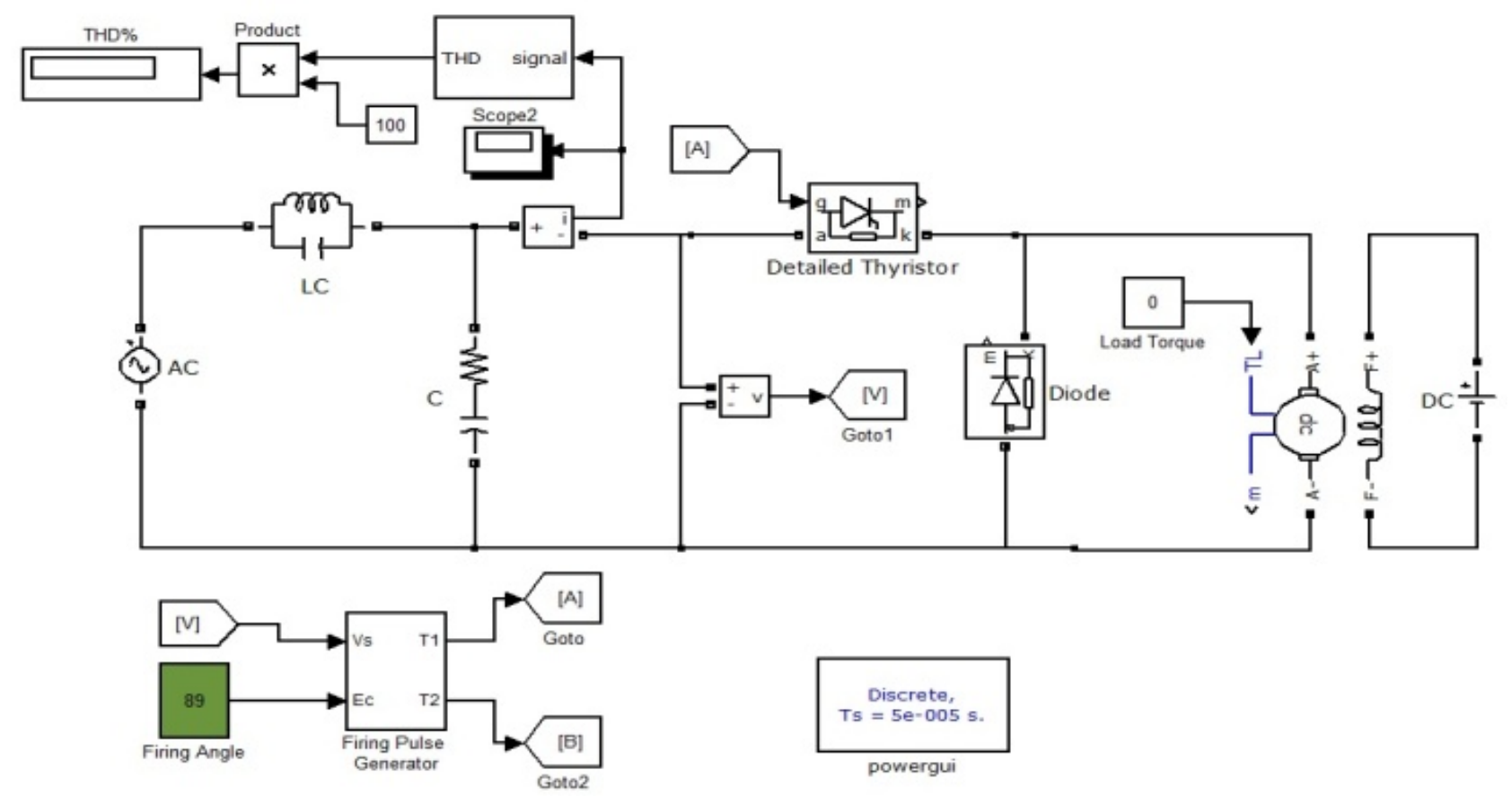

(a). 


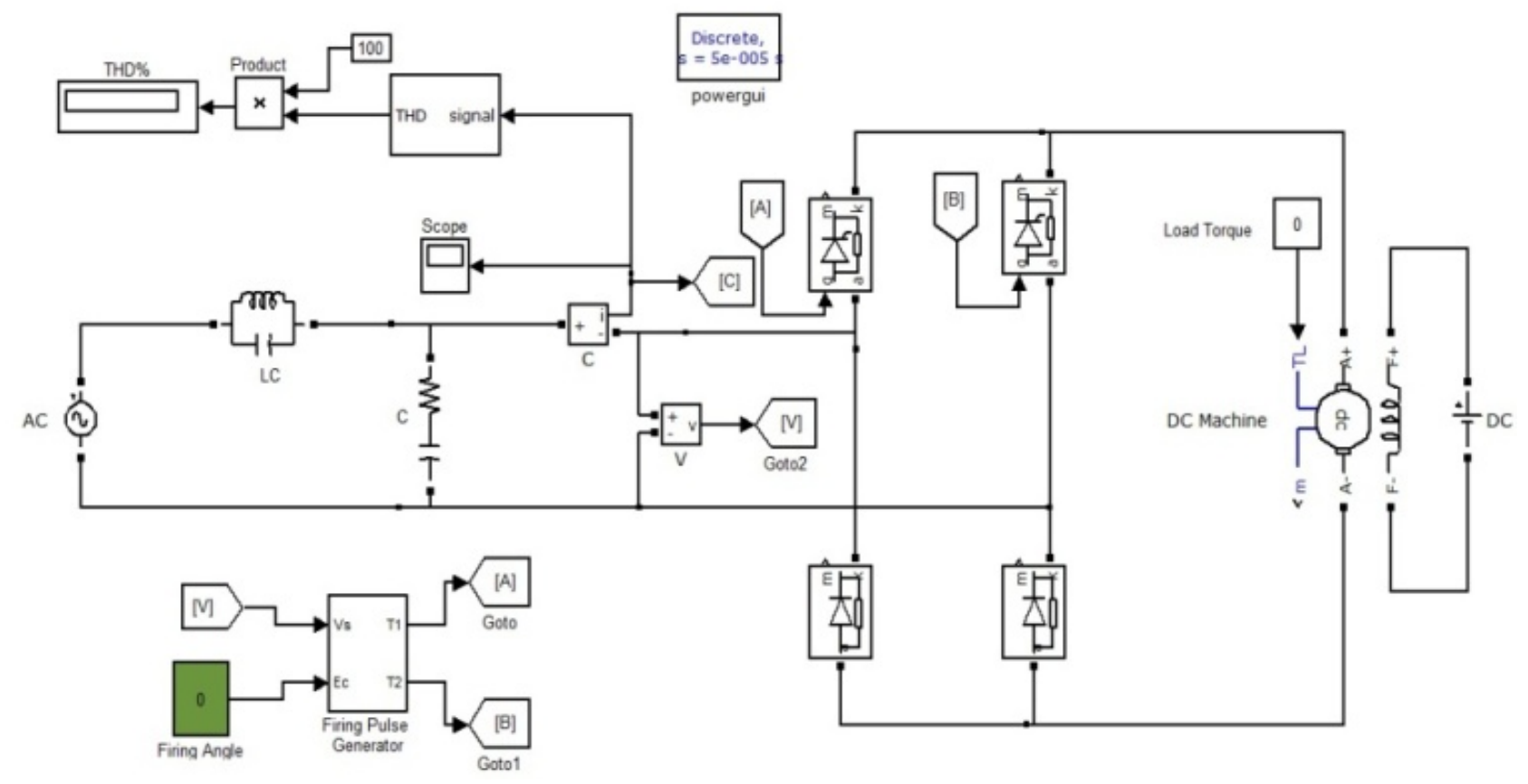

(b). 


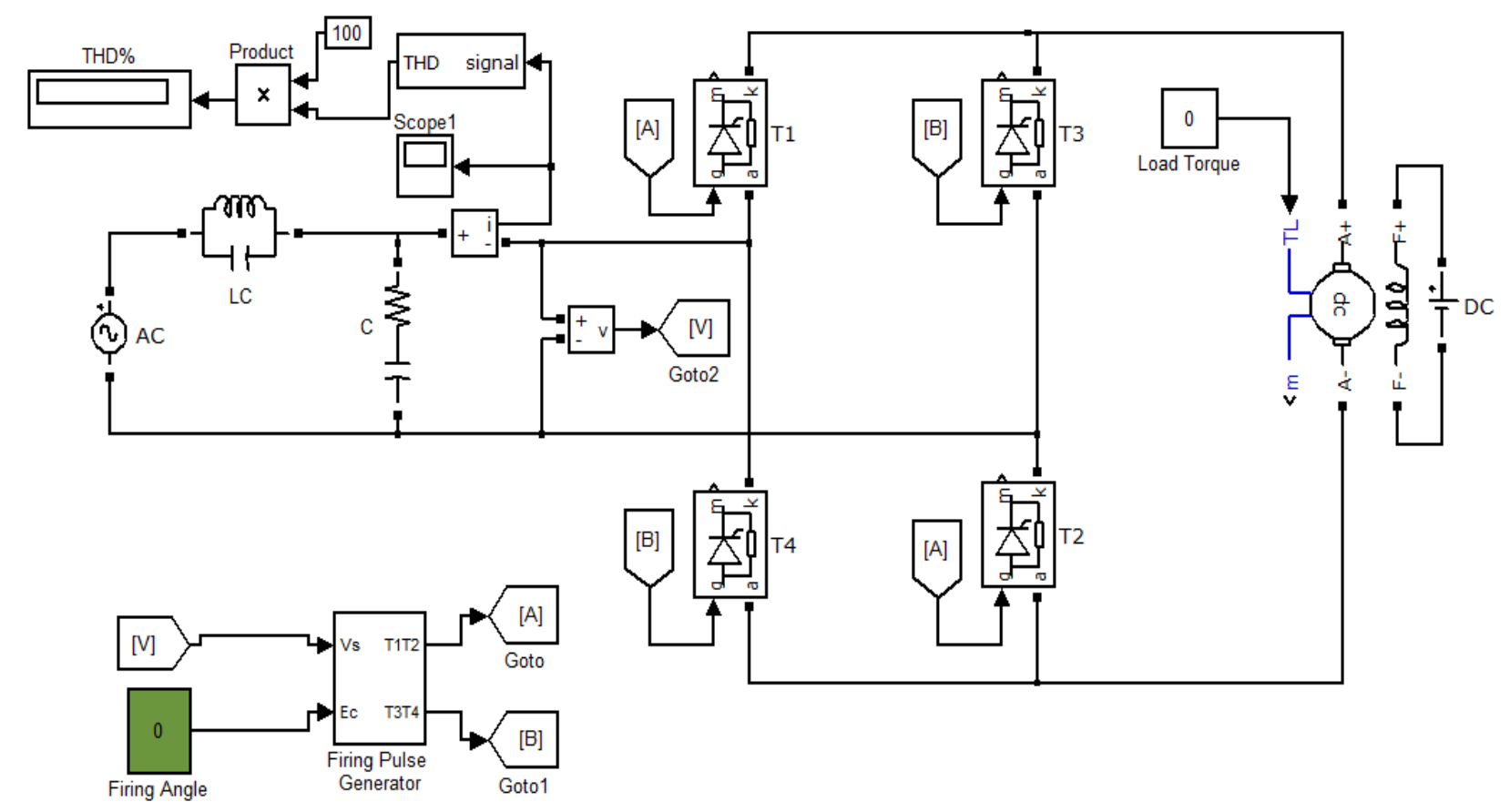

(c). 


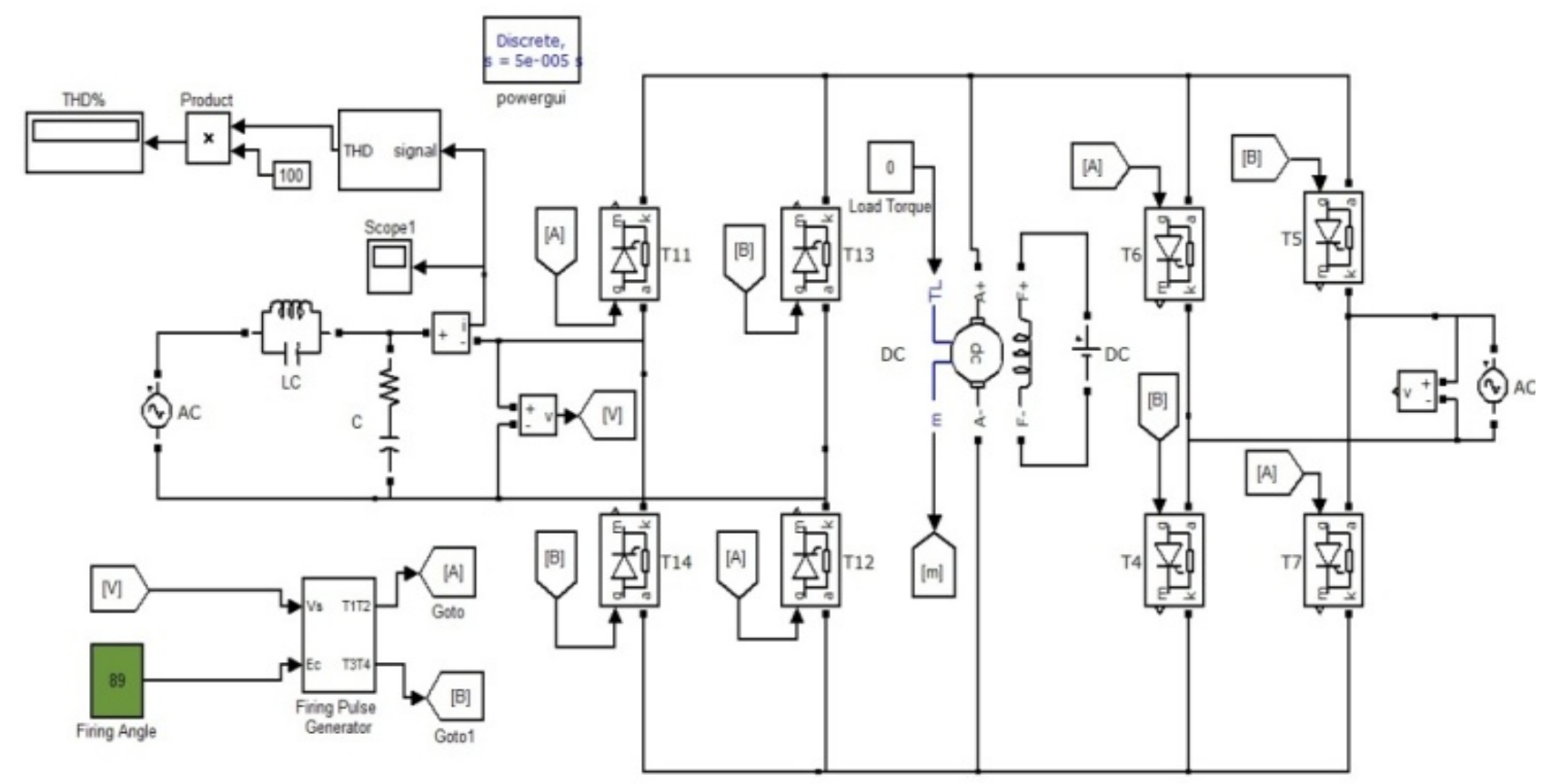

(d).

Figure 9. Converter drives with PFC circuit

(a) Half wave converter drivi

(b) Semiconverter drive

(c) Full converter drive

(d) Dual converter drive 
Rohit Gupta, et al.

Table 7 and 8 shows the value of power factor, improved power factor, total harmonic distortion with improved total harmonic distortion for different type of converter drives at firing angle $89^{\circ}$.

Table 7. Comparison of PF for different drives

\begin{tabular}{|l|c|c|c|c|}
\hline Type of drive & $\begin{array}{c}\text { Firing } \\
\text { angle }\end{array}$ & PF & $\begin{array}{c}\text { Improved } \\
\text { PF }\end{array}$ & $\begin{array}{c}\text { \% improvement } \\
\text { in }\end{array}$ \\
\hline $\begin{array}{l}\text { Half wave converter } \\
\text { drive }\end{array}$ & 89 & 0.42 & 0.78 & 85 \\
\hline Semi converter drive & 89 & 0.43 & 0.71 & 65 \\
\hline $\begin{array}{l}\text { Full wave converter } \\
\text { drive }\end{array}$ & 89 & 0.37 & 0.68 & 83 \\
\hline Dual converter drive & 89 & 0.61 & 0.99 & 62 \\
\hline
\end{tabular}

Table 8. Comparison of $\%$ THD for different drives

\begin{tabular}{|l|c|c|c|c|}
\hline Type of drive & $\begin{array}{c}\text { Firing } \\
\text { angle }\end{array}$ & \% THD & $\begin{array}{c}\text { Improved } \\
\text { \%THD }\end{array}$ & $\begin{array}{c}\text { \% } \\
\text { Improvement in } \\
\text { THD }\end{array}$ \\
\hline Half wave converter drive & 89 & 104.8 & 11.24 & 89 \\
\hline Semi converter drive & 89 & 56 & 4.08 & 92 \\
\hline Full wave converter drive & 89 & 38.96 & 3.6 & 90 \\
\hline Dual converter drive & 89 & 65 & 10.73 & 84 \\
\hline
\end{tabular}
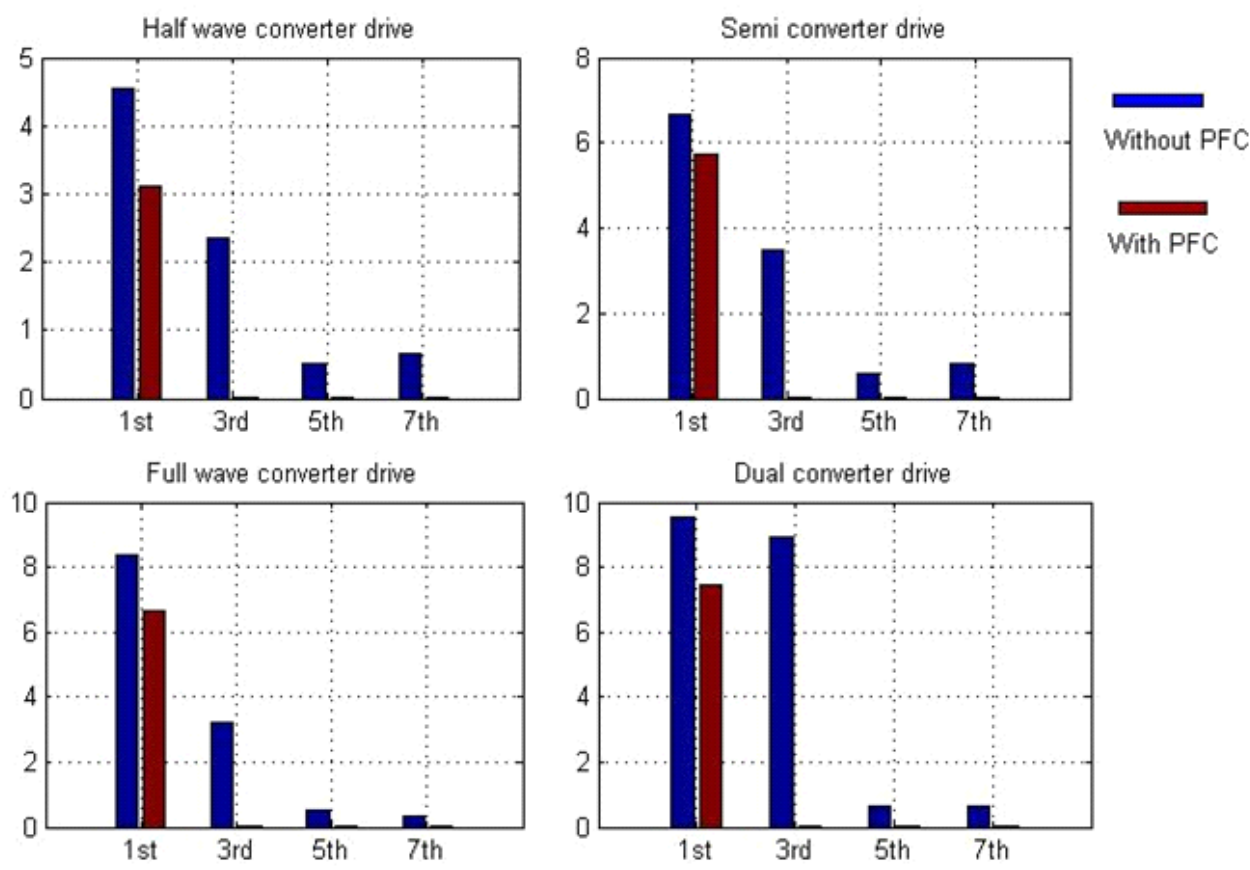

Figure 10. Current harmonics for different drives

Figure 10 shows the input current harmonics (odd) with and without power factor correction, and Table 9 shows the percentage reduction in current harmonics for different drives, which shows a remarkable reduction in $3^{\text {rd }}$ harmonics for which the power factor correction circuits are designed. 
Table 9. Comparison of current harmonics for different drives

\begin{tabular}{|l|c|c|c|c|}
\hline \multirow{2}{*}{ Type of drive } & \multicolumn{4}{|c|}{ Percentage reduction in current harmonics } \\
\cline { 2 - 5 } & $\mathbf{1}^{\text {st }}$ & $\mathbf{3}^{\text {rd }}$ & $\mathbf{5}^{\text {th }}$ & $\mathbf{7}^{\text {th }}$ \\
\hline $\begin{array}{l}\text { Half wave } \\
\text { converter drive }\end{array}$ & 31.78022 & 99.98306 & 99.23547 & 99.40972 \\
\hline $\begin{array}{l}\text { Semi converter } \\
\text { drive }\end{array}$ & 14.00843 & 99.93974 & 99.46487 & 99.4283 \\
\hline $\begin{array}{l}\text { Full wave } \\
\text { converter drive }\end{array}$ & 20.90725 & 99.98124 & 99.66041 & 99.11196 \\
\hline $\begin{array}{l}\text { Dual converter } \\
\text { drive }\end{array}$ & 21.8589 & 99.95297 & 99.79256 & 99.57109 \\
\hline
\end{tabular}

\section{Conclusions}

In the above discussion, five types of power factor improvement topologies are implemented and their performance is compared on the basis of five parameters those are power factor, input current distortion factor, input current harmonic factor, input displacement factor and total harmonic distortion, and it is found that the single phase diode rectifier circuit with improved parallel input resonant filter performs well. Thus the same parallel input resonant filter is applied with different types of DC drives systems which are single phase half wave converter drive, single phase semiconverter drive, single phase full converter drive and single phase dual converter drive, and a significant improvement of $85 \%$ for half wave converter drive, $65 \%$ for semi converter drive, $83 \%$ for full converter drive and $63 \%$ for dual converter drive in power factor is observed and similarly in total harmonic distortion percentage improvement is $89 \%, 92 \%, 90 \%$, and $84 \%$ respectively.

But selection of filter components still involves complex mathematical calculations, so the selection of components can be done by applying artificial intelligence.

APPENDIX A

The parameters of separately excited DC motor

\begin{tabular}{|l|c|}
\hline \multicolumn{1}{|c|}{ Rated Power (P) } & $\mathbf{5 ~ H p}$ \\
\hline Rated Armature Voltage & $240 \mathrm{~V}$ \\
\hline Armature Resistance $R_{a}$ & $2.518 \Omega$ \\
\hline Armature Inductance $L_{a}$ & $0.028 \mathrm{H}$ \\
\hline Field Resistance $R_{f}$ & $281.3 \Omega$ \\
\hline Field Inductance $L_{f}$ & $156 \mathrm{H}$ \\
\hline Rated Speed & $1750 \mathrm{RPM}$ \\
\hline Rated Field Voltage & $300 \mathrm{~V}$ \\
\hline
\end{tabular}

\section{References}

[1] S. J. Chapman, Electric Machinery Fundamentals, New York: WCB/McGraw-Hill, 1998.

[2] D. A. staton, M. I. McGilp and T. J. E. Miller, "DC machine teaching experiment," in proceedings of the European Power Electronics Association EPE, Brighton, pp. 35 - 40, 1993

[3] W. M. Daniels and A. R. Shaffer, "Re-inventing the electrical machines curriculum," IEEE Transactions on Education, vol. 41, pp. 92-100, May 1998.

[4] N. Mohan, Electric Drives: An integrative approach, University of Minnesota Printing services, 2000. 
[5] M. Nedeljkovic and Z. Stojiljkovic, "Fast current control for thyristor rectifiers," IEE Proceedings- Electr. Power Appl., Vol. 150, No. 6, pp. 636-638, Nov. 2003.

[6] Alfio Consoli, Mario Cacciato, Antonio Testa and Francesco Gennaro, "Single Chip Integration for Motor Drive Converters With Power Factor Capability," IEEE Transactions on Power Electronics, Vol. 19, No. 6, pp. 1372-1379, Nov. 2004.

[7] S. Li and R. Challo, "Restructuring an electric machinery course with an integrative approach and computer-assisted teaching methodology," IEEE Transactions on Education., vol. 49,pp. 16-28, Feb.2006.

[8] Manoj Daigavane, Hiralal Suryawanshi and Jawed Khan, "A Novel Three Phase SeriesParallel Resonant Converter Fed DC-Drive System,” Journal of Power Electronics, Vol. 7, No. 3, pp. 222-232, July 2007.

[9] Wai Phyo Anug, "Analysis on Modeling and Simulink of DC Motor and its Driving System Used for Wheeled Mobile Robot," World Academy of Science, Engineering and Technology 32, pp. 299-306, 2007.

[10] A. Gelen and S. Ayasun, "Effects of PWM chopper drive on the torque-speed characteristic of DC motor" $43^{\text {rd }}$ International Universities Power Engineering Conference, 2008.

[11] P. S. Bhimbhra, Power Electronic, Khanna publishers, 2010.

[12] S. B. Dewan, "Optimum input and output filters for a single-phase rectifier power supply," IEEE Trans. Industry Appl., vol. IA-17, no. 3, pp. 282-288, 1981.

[13] A. R. Prasad, P. D. Ziogas and S. Manias, "A novel Passive wave-shaping method for single phase Diode Rectifiers", IEEE Trans. on Industrial Electronics, Vol.37, No.6, pp. 521-530, Dec.1990.

[14] F. C. Schwarz, "A Time-Domain Analysis of the Power Factor for a Rectifier Filter System with over- and Subcritical Inductance", IEEE Trans. Ind. Electron. Control Instru. IECI-20(2), pp. 61-68, 1973.

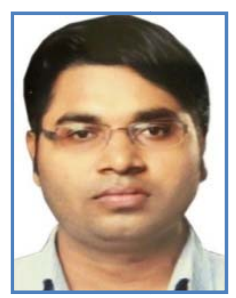

Intelligence.

Rohit Gupta is working as an Assistant Professor in the Electrical and electronics Department at Noida Institute of Engineering and technology, Greater Noida, India. He is graduated in Electronics and Instrumentation Engineering from Uttar Pradesh Technical University, India and post graduated in Instrumentation and Control Engineering from Thapar University, Patiala, Punjab, India. He is Student Member of Metrology Society of India, National Physical Laboratory, New Delhi. His major research areas are Control systems, Image Processing and Artificial

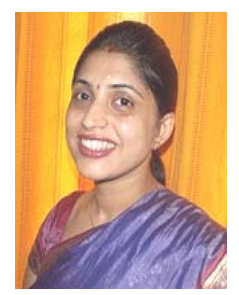

Ruchika is working as Lecturer in the Electrical and instrumentation Engineering Department at Thapar University, Patiala, Punjab, India. She received her graduate degree in Instrumentation and Control Engineering from Kurukshetra University, Kurukshetra, Haryana, India in 2005 and ME degree in Instrumentation Engineering from National Institute of Technical Teachers Training and Research, Chandigarh, India, in 2009. She received S P Luthra Gold Medal along with Academic award at Post Graduation level. She teaches undergraduate and postgraduate courses in Electrical and instrumentation engineering. Her major research interests are Image Processing, Microcontroller, and Bio medical Instrumentation. 